\title{
INTRODUCTION ENVIRONMENT, DEVELOPMENT AND SUSTAINABILITY
}

\author{
Muhammad Aqeel ASHRAF ${ }^{1,2 *}$ Claudio M. AMESCUA GARCÍA ${ }^{3}$ \\ and Ahmed Jalal Khan CHOWDHURY ${ }^{2,4}$
}

${ }^{1}$ Department of Environmental Science \& Engineering, School of Environmental Studies, China University of Geosciences 430074 Wuhan, China

${ }^{2}$ International Water, Air \& Soil Conservation Society INWASCON 59200 Kuala Lumpur, Malaysia

${ }^{3}$ Centro de Ciencias de la Atmósfera, Universidad Nacional Autónoma de México

${ }^{4}$ Department of Marine Science, Kulliyyah of Science, International Islamic University, Malaysia, 25200 Kuantan, Pahang, Malaysia

\section{INTRODUCTION}

Environmental sustainability can be elaborated as a perfect and reliable interaction with the environment to put an end to the exploitation and degradation of natural resources to establish a more positive association with the environment (Sheng 2019). Acts of environmental sustainability have perfectly helped to provide the needs of current world's population without compromising over the things that are helpful for the upcoming generations to meet their needs. Economic development, social development and environmental protection are the crucial parts of sustainability. The best and widely used measure for the well-being is Environmental Performance Index (EPI) (A1 Islam et al. 2019). But the disadvantage of this index is that it does not look at the notion of sustainability, in simple terms, it does not have the environmental component specification. In contrast to it, we have useful data gathered from different sources that provides information about the environmental health of countries but not about the human development, such as the EP (u1 Ain et al. 2019).

Environmental governance advocates sustainability as the supreme consideration in managing all human activities - political, social and economic (Ogunkunle et al. 2019, Youdeowei et al. 2019). The concept of sustainability relies on sustainable development. Sustainable development can be explained in various ways, but the most widely recognized definition was phrased by the Brundtland Commission in 1987:
"Sustainable development is development that meets the needs of the present without compromising the ability of future generations to meet their own needs."

Sustainable development is based on the three pillars of sustainability: economic, environmental and social sustainability. It is only achieved when there is balance or a trade-off between these three aspects (Fig. 1).

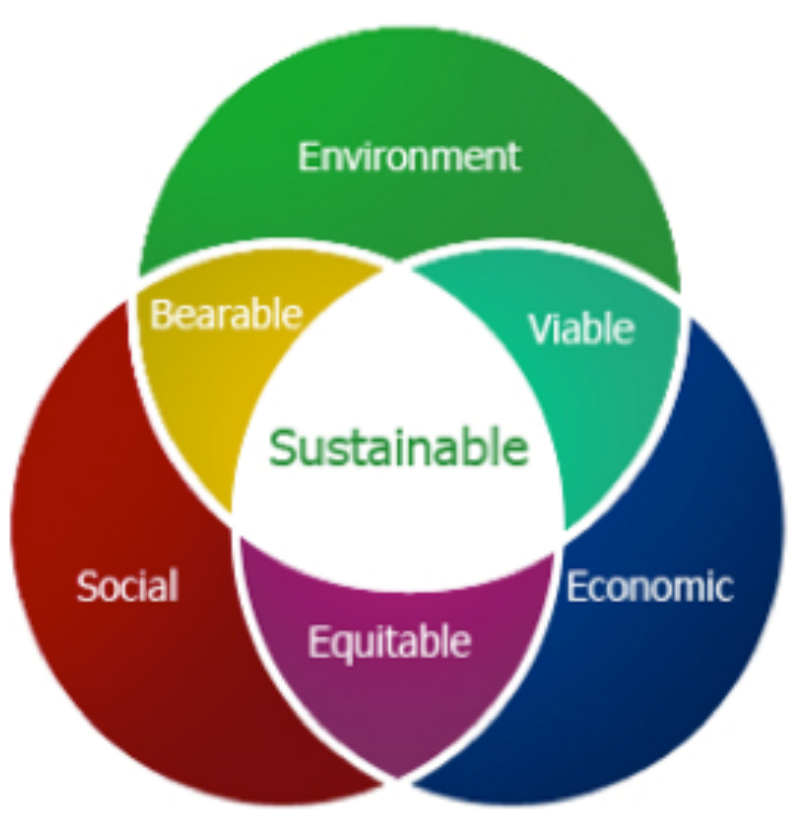

Fig. 1. Relationships in sustainable development - environmental, social and economic concerns. 
However, some authors have expanded this approach and added a fourth pillar (for example cultural, political or institutional). It is most important to understand that sustainable development is a holistic, integrated approach, meaning that in order to achieve sustainable development, there needs to be a balance between different spheres of life. The natural resources base and ecosystems must be managed sustainably to meet people's food requirements and other environmental, social and economic needs (Jalal et al. 2018). Climate change, increased water scarcity and conflicts over access to resources all pose challenges to environmental sustainability and food security. Hunger and poverty often compel the poor to over-exploit the resources on which their own livelihoods depend. Strategies, polices and institutions for conserving, protecting, and enhancing natural resources should be strengthened to provide an enabling environment and should be based on the specific resource constraints faced in any given location (Zhang et al. 2018, Diego et al. 2019).

Environmental sustainability is indispensable to sustainable development associated with the complex interactions between environment and the development. The objective of this special issue is to find those ways and means that can help to achieve sustainability in all human activities for such development (Kamal et al. 2019). Applying an integrated approach to public planning consists not only in incorporating the environmental components in the plans and social and economic development projects, but also in promoting a sectoral and cross-sectoral balance between social development, sustained economic growth and the sustainable management of natural resources and ecosystems (Amamra et al. 2019, Zhao et al. 2019).

This special issue covers the interactions among society, development and environment, and how implications of those interactions are needed for sustainable development. It sheds light on technical, economic, ethical and philosophical aspects of sustainable development with respect to local, regional and global sustainability and their practical implementation, which is development and application of indicators of sustainability; development, verification, implementation and monitoring of policies for sustainable development -the sustainable use of land, water, energy and biological resources in the development, looking at the impacts of agriculture and forestry activities on soil and aquatic ecosystems and biodiversity, and much more (Wang 2019).

This introduction provides a general frame to the documents of this special issue. The papers separately discuss the development of new ideas or theories, and they also provide new perspectives on the existing ones by opening a new vista to the concerned approach in order to put a separate emphasis on the construction of new theories and research domains. But still it is needed strong conceptual thinking faculty in the development of ideas. To highlight concerned material, we have presented the different types of conceptual contributions in the current papers. This is done just to emphasize over the need of refined skills and thinking to produce good conceptual research papers. And we anticipate by hoping that this emphasis will provide a new and strong impetus to the readers, so they would use their best faculties to produce reliable and fruitful conceptual works in the future. We also hope that these papers will inspire the readers to facilitate this field and bring more advancement to it.

Overall, the papers published in this Special Issue illustrate the large array of ongoing research in the field of environmental toxicology of trace metals that span from aquatic to terrestrial environments, from mechanistic subcellular to more applied basin scale research, from analytical measurements, effect-oriented research with various organisms to modelling and field studies. Just like the whole field of environmental sciences, the subjects in this issue are also strongly interdisciplinary. Most of the contributions are based on latest research findings from China, and ranges in focus from the forests and watersheds to the conservation challenges and the links between environmental and social change. We would like to thank Revista Internacional de Contaminación Ambiental who provided the opportunity to publish this special issue. We hope you will find those presented thoughts and results inspiring when you read this issue.

\section{REFERENCES}

Al Islam S., Javaid Z., Ghaffar A., Jamil Y. and Warraich, N.A. (2019). A study on gamma radiation response of ceric sulfate dosimeter. Acta Scientifica Malaysia $3(1), 5-8$.

Amamra A. and Khanchoul K. (2019). Water quality of the Kebir Watershed, northeast of Algeria. Journal Clean Was 3(1), 28-32.

Diego H., Zen M. and Karen M. (2019). Analysing trade-offs in management decision-making between ecosystem services, biodiversity conservation, and commodity production in the Peruvian Amazon National Reserve. Environment \& Ecosystem Science 3(2), 01-08. 
Jalal K.C.A., Alifah F.K., Faizul H.N.N., Mamun A.A., Kader M.A. and Ashraf M.A. (2018) Diversity and community composition of fishes in the Pusu River (Gombak, Malaysia). Journal of Coastal Research: Special Issue 82 - Coastal Ecosystem Responses to Human and Climatic Changes throughout Asia. 150-155.

Kamal M., Younas R., Zaheer M. and Shahid M. (2019). Treatment of municipal waste water through adsorption using different waste biomass as activated carbon. Journal Clean Was. 3(1), 21-27.

Ogunkunle T.J., Adewumi A. and Adepoju A.O. (2019). Biodiversity: Overexploited but underutilized natural resource for human existence and economic development. Environment \& Ecosystem Science 3(1), 26-34.

Sheng N. (2019). Research on arbitrary virtual view image synthesis method of two views. Science Heritage Journal 3(1), 24-31.

ul Ain Q., Rehman G. and Zaheer M. (2019). An analysis of an underground water flow using Adomian decomposition method. Water Conservation and Management $3(1), 27-29$.
Wang T.L. (2019). Nonlinear control strategies and planning for under actuated overhead cranes. Engineering Heritage Journal 3(1), 09-12.

Youdeowei P.O., Nwankwoala H.O. and Desai D.D. (2019). Dam structures and types in Nigeria: sustainability and effectiveness. Water Conservation and Management 3(1), 20-26.

Zhang M.H., Sun Z.C., Sun J.W., Suo A.N. and Ashraf M.A. (2018) Evaluation method for effective coastal repair in Moon Bay, Yingkou, China. Journal of Coastal Research: Special Issue 82-Coastal Ecosystem Responses to Human and Climatic Changes throughout Asia. 186-192.

Zhao L. and Wang W.S. (2019). Parametric architectural design based on optimization algorithm. Engineering Heritage Journal 3(1), 13-17. 